\title{
The Effects of Air-Gap Width on Performance of Brushless Doubly Fed Machine with Radial Laminated Reluctance Rotor
}

\author{
Qian Zhang ${ }^{1,}$, Zhenyang Zhang ${ }^{1, b}$ and Huijuan Liu ${ }^{1, c}$ \\ ${ }^{1}$ School of Electrical Engineering, Beijing Jiao tong University, Beijing 100044, China \\ a08122011@bjtu.edu.cn, b14121514@bjtu.edu.cn, chjliu@bjtu.edu.cn
}

\begin{abstract}
Keywords: radial laminated reluctance rotor; brushless doubly fed machine; air-gap; finite element Abstract. A new type of AC variable speed brushless doubly fed machine with radial laminated reluctance rotor (RLR-rotor BDFM) is presented and analyzed in this paper. The rotor of the BDFM is structured by the radial reluctant lamination, and the electric brushes and slip ring are cast off. Therefore, this machine will be more reliable. The BDFM proposed in this paper can work under different modes--asynchronous operation, synchronous operation, super-synchronous operation and sub-synchronous operation, and its active and reactive power can easily be regulated. It has a good application prospect in converter-fed variable speed drive applications and variable-speed constant-frequency (VSCF) wind power generation systems. Firstly, this paper introduces RLR-rotor structure, the transient flied of the motor with three different air-gap widths is calculated by finite element method. Then the air-gap flux distribution and voltages of power winding with no-load operation are analyzed. The torque curves of these motors are plotted according to the calculation results, and the voltage of the power windings and harmonic contents at the maximum torque are solved. All the results indicate the effects of air-gap widths on machines, and provide insights into rotor structure optimization of RLR-rotor BDFM.
\end{abstract}

\section{Introduction}

Recently, a lot of domestic and international experts and scholars pay more attention to the BDFM. This machine achieves doubly fed on the brushless stator winding with simple structure of rotor and has excellent properties of asynchronous and synchronous machines simultaneously. That's to say it not only can work as AC variable speed machine, but a VSCF machine. Due to the realization of brushless, the reliability of this machine is higher, meanwhile, the capacity of transducer is smaller and the fabrication cost of this motor is lower. As a new type of motor, especially on the aspect of new energy and wind power, the research about it is in the course of forming and developing rapidly.

The common rotor structure of BDFM can be divided into two categories: cage rotor and reluctance rotor, and each type has its own structure pattern. The hybrid rotor combined cage rotor and reluctance rotor was proposed at home.

With several years of development, the domestic and international universities and scholars have done some researches about the BDFM. In [1-5], the reluctance rotor BDFM has been researched. Some new structures of BDFM were proposed in [6-7], such as high-temperature superconducting motor and permanent magnet motor. In [8-13], the emphasis of the research had been shifted to the optimization of BDFM, for instance, reducing the voltage harmonic content, optimizing the winding and magnetic circuit [12], and studying the effect of ferromagnetic materials on torque [13]. Some researches about the loss of motor were deeply analyzed in [14], and other scholars investigated in the aspect of control strategies of motor, achieved the better performance of low speed motor, and studied the MPPT control of the motor in the field of power generation. Vibration and noise as the inevitable problems in the application also were researched certainly.

A new novel of RLR-rotor BDFM has been put forward, the new match way (the stator winding -4 poles/ 6 poles and rotor-10 poles) about the pole-pairs of stator and rotor is showed. With the 2D FEM analysis, the performance of BDFMs with two kinds of air-gap length is calculated. Then the flux distribution and the output torque of the two proposed BDFMs have been investigated. The condition of producing maximum electromagnetic torque has been analyzed and the power, voltage of winding 
and harmonics of one BDFM to another has been compared when they get the maximum torque. These investigates will provide valid theoretical basis for the optimization and design of the machine.

\section{The Structure and Principle of the RLR-rotor BDFM}

Fig. 1 shows the structure model of the proposed RLR-rotor BDFM. There are two sets of three phase sinusoidally distributed windings with different pole-pairs number on stator of a BDFM. The primary winding with p pairs of poles (also called power winding) is connected directly to the power grid. And the secondary winding with q pairs of poles (also called control winding) is supplied with variable voltages at variable frequencies from a converter connected to the power grid. There is no directly magnet coupling between the two sets of windings, so to realize the converting of electromechanical energy, it's essential to utilizing the special structure of rotor to modulate the flux filed of two sets of windings. As for the stator winding, there are single winding structure and double windings structure. The former has advantages of higher slot fullness and lower copper losses, but affected by the match of stator pole-pairs number, the design is complicated. The latter is designed more easily and superior to the former in the coupling characteristics between the two sets of windings. Therefore, the dual windings structure is adopted as the stator winding in this paper. For the rotor, RLR-rotor is accepted. The rotor punched segments is showed in Fig.2. Comparing to the cage rotor in [9-10] and the ALA rotor in [11], the manufacture of RLR-rotor is more easily realized. Taking into account the advanced laminating technology for cold-rolled silicon steel sheet, the lower core loss and higher efficiency are achieved with utilization of RLR-rotor.

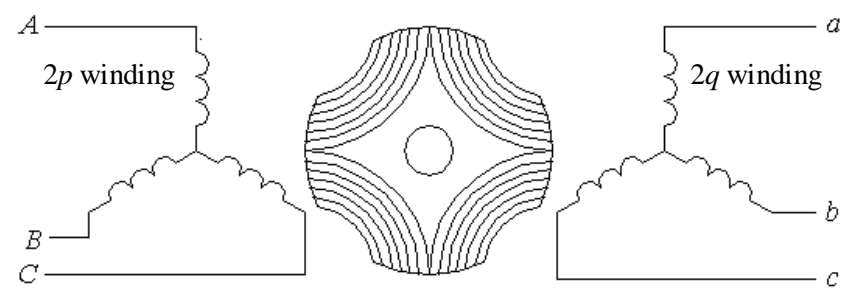

Fig 1. Schematic diagram of RLR-rotor BDFM

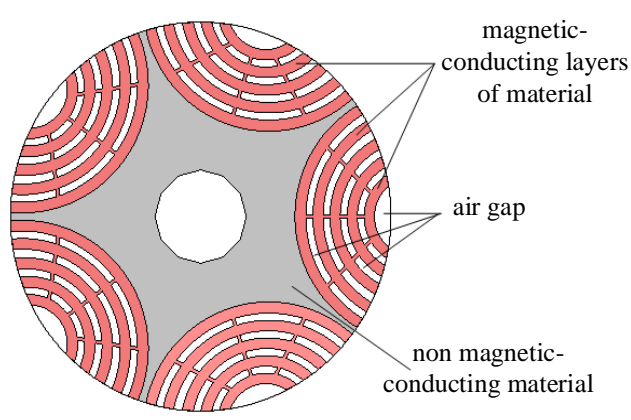

Fig 2. Schematic diagram of RLR-rotor sheet

When the power winding and control winding of this machine is charged the three-phase symmetric sinusoidal current with frequency $f_{1}$ and $f_{2}$ respectively, the pole-pairs number $p_{r}$ is equal to the sum of $\mathrm{p}$ and $\mathrm{q}$ and the frequency $\left(f_{1}\right.$ and $\left.f_{2}\right)$ of winding currents and the speed $\mathrm{nr}$ of motor meet the condition of constraint in formula (1), the three-phase back EMFs with a frequency of $f_{1}$ in the primary windings and a frequency of $f_{2}$ in the control windings will be induced respectively, and the stable electromagnetic torque is emerged, the exchange of electromechanical energy can be realized further .

$$
n_{r}=60\left(f_{1} \pm f_{2}\right) / p_{r}
$$

Where we get the sum of $f_{1}$ and $f_{2}$ when the current phase sequence of the power winding and control winding are same, on the contrary, we get the difference. 
According to the formula (1), the different operations of the proposed BDFM can be got as follows: when the power winding is connected directly to the power grid, the machine will work at asynchronous operation if the control winding is shorted by a resistor, and the machine will work at synchronous mode with the speed of $60 f_{1} / p_{r}$ if the control winding is excited by DC current. While when the control winding is supplied with variable voltages at variable frequencies from a converter connected to the power grid, the motor will run at super-synchronous operation if we get the sum of $f_{1}$ and $f_{2}$ in formula (1), and if we get the difference, it will run at sub-synchronous operation.

Therefore, the current frequency $f_{2}$ of control winding can be adjusted to change the speed $n_{r}$ of the machine and achieve the operation of frequency-changing speed regulation when the machine is as a motor. The excited current of control winding can be modulated following the variation of speed $n_{r}$ to keep the constant frequency $f_{l}$ of power winding and achieve the mode of VSCF when the machine is as a generator.

\section{The 2D FEM Model of the RLR-rotor BDFM}

The performances of RLR-rotor BDFM $(150 \mathrm{~kW})$ with different air-gap width are computed using FEM. The parameters of machine are showed in Table1.

Table 1. Parameters of machine

\begin{tabular}{|l|c|c|}
\hline \multicolumn{1}{|c|}{ Parameters } & Air-gap $(0.8 \mathrm{~mm})$ & Air-gap $(1.2 \mathrm{~mm})$ \\
\hline Inside diameter of stator $(\mathrm{mm})$ & 250.5 & 250.5 \\
\hline Pole-pairs of stator & $p=2 / q=3$ & $p=2 / q=3$ \\
\hline Excited current of stator(A) & 240 & 240 \\
\hline Outside diameter of rotor $(\mathrm{mm})$ & 249.7 & 249.3 \\
\hline Pole-pairs of rotor & 5 & 5 \\
\hline
\end{tabular}

It's necessary to select the cross section of entire motor as solving area for the asymmetrical magnetic field. In order to calculate conveniently, the following assumptions have been proposed [9]:

(1) Ignore the motor end effect.

(2) Stator winding charged into the three-phase symmetrical current is put in the slot, and magnetic field along the axial distributes symmetrically and has no other direction components.

(3) The material of core laminations is the same, and it has the single value B-H curve.

(4) Ignore the external flux field of solving area.

(5) Ignore the core loss of the machine.

In order to accurately compare the effects of air-gap width on the performance of the motor, the winding excitations for the two motors are set the same value as the transient field was calculated. The FEA model of this motor is exhibited in Fig.3.

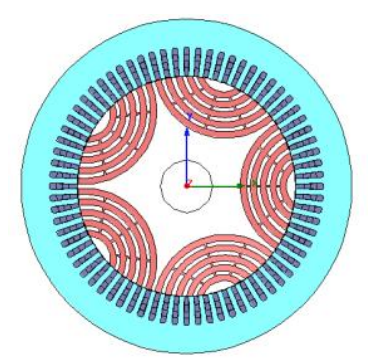

Fig 3. FEM model of the motor

\section{Performance of the RLR-rotor BDFM at No-load}

Induced EMF

The EMF of no-load can be researched when the power winding is open and the control winding is excited by a certain frequency current with the same initial phase. The frequency of induced voltage of power winding can be the same if the relationship between $n_{\mathrm{r}}$ and the excited frequency $f_{2}$ of the 
control winding was chosen as showed in Table2. When the excited amplitude value and the initial phase of control winding is $240 \mathrm{~A}$ and zero degree respectively, the no-load induced EMF (phase A) of power winding of the motor with 0.8 and $1.2 \mathrm{~mm}$ air-gap width of different exciting frequency are showed in the Fig.4.

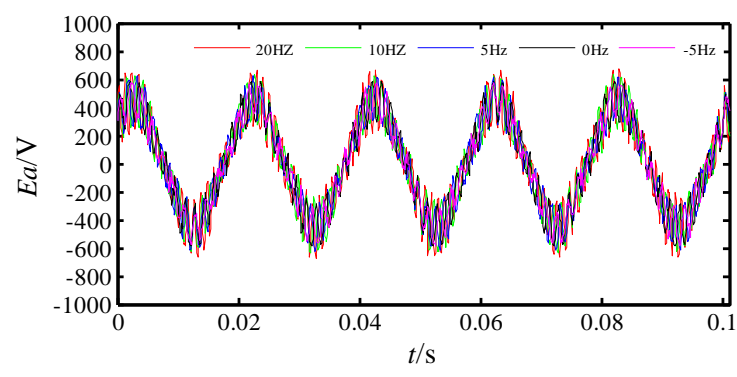

(a) Air-gap width of $0.8 \mathrm{~mm}$

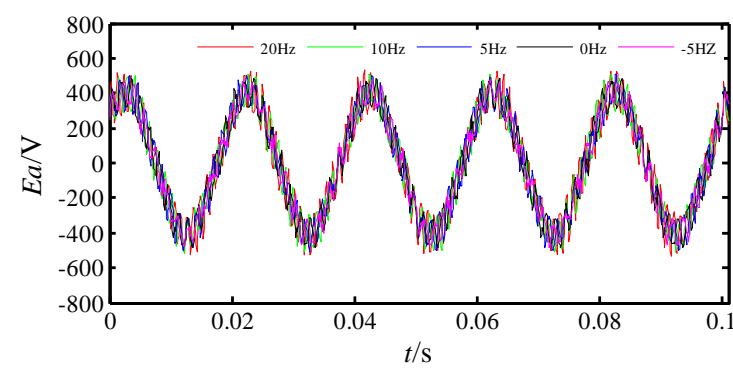

(b) Air-gap width of $1.2 \mathrm{~mm}$

Fig 4. No-load voltages of power windings with different excited frequency

The Fourier decomposition method was used to solve the induced EMF of power winding calculated by FEM, The power winding's fundamental amplitudes of the EMF of the two motors are given in Table2. The induced EMF $\mathrm{E}_{\mathrm{a}}$ of the power winding keep the constant phase and amplitude with different exciting frequency. Compared to the two motors with different air-gap width, the fundamental voltage amplitude $(450 \mathrm{~V})$ of motor with air-gap width $0.8 \mathrm{~mm}$ is larger than the motor $(400 \mathrm{~V})$ with $1.2 \mathrm{~mm}$. It indicates that the size of the air-gap width on the fundamental voltage amplitude of power winding is significant.

Table 2. No-load voltage amplitude

\begin{tabular}{|c|c|c|c|}
\hline \multirow{2}{*}{$f_{2}(\mathrm{~Hz})$} & \multirow{2}{*}{$n_{r}(\mathrm{r} / \mathrm{min})$} & \multicolumn{2}{|c|}{ Air-gap width(mm) } \\
\cline { 3 - 4 } & & 0.8 & 1.2 \\
\hline 20 & 840 & 448.15 & 402.39 \\
\hline 10 & 720 & 446.52 & 401.54 \\
\hline 5 & 660 & 451.23 & 404.75 \\
\hline 0 & 600 & 446.24 & 402.12 \\
\hline-5 & 540 & 449.3 & 402.5 \\
\hline
\end{tabular}

Flux density of air-gap

The spectrum analysis on the flux density of two kinds of air-gap has been done in order to reveal the coupling performance of the motor clearer. The harmonic amplitude of flux density of air-gap with different width from the 1th to the 30th is showed in Fig. 5(a) and (b). Taking account of the accuracy, the control windings (6-pole winding) of two motors all are excited with AC current of $20 \mathrm{~Hz}$ and the amplitude of $240 \mathrm{~A}$, the motor speed is $840 \mathrm{r} / \mathrm{min}$.

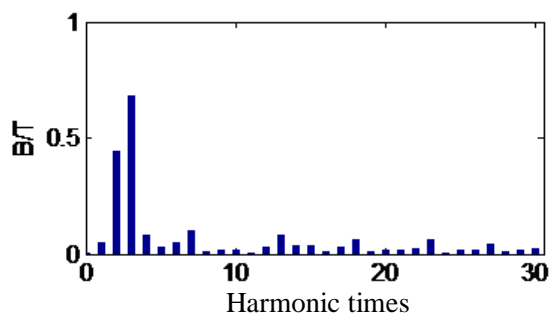

(a) Air-gap width of $0.8 \mathrm{~mm}$

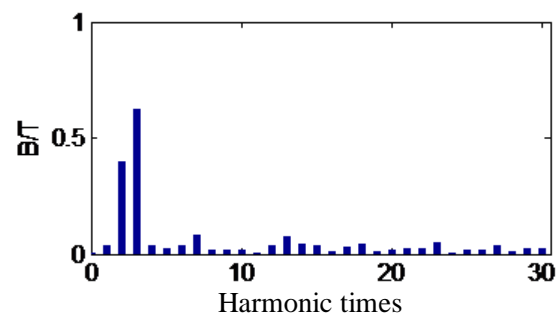

(b) Air-gap width of $1.2 \mathrm{~mm}$

Fig 5. Harmonic contents of air-gap flux

In Fig.5, the 2nd component indicates 4-pole magnetic flux distribution; and the 3rd indicates the 6-pole distribution. It can be seen that when the control winding is excited, the mutual coupling flux is 4-pole flux component. This phenomenon shows that the radial laminated reluctance rotor can modulate the flux field as the reluctance rotor and cage rotor. 
The mutual coupling flux indicates the coupling of the two stator windings which determines the capability of electromechanical energy conversion. The mutual coupling flux hoped to be larger while the self-coupling flux smaller for it contributes nothing to electromechanical energy conversion. Obviously, when the air-gap width is $0.8 \mathrm{~mm}$ and $1.2 \mathrm{~mm}$ respectively, the self-coupling flux is 0.683 $\mathrm{T}$ and $0.622 \mathrm{~T}$, and the mutual coupling flux is $0.44 \mathrm{~T}$ and $0.4 \mathrm{~T}$ respectively. That $\mathrm{s}$ to say, increasing the air-gap width will lower the electromechanical energy conversion ability.

\section{Performance of the RLR-rotor BDFM at Load}

The formula of Torque

When one set of stator winding (such as control winding) is excited by DC or AC Current, induced speed voltage will be induced in the other winding while rotation of rotor. If the currents with the same frequency as the mutual flux linkage variation are injected into the second windings (power winding), the steady electromagnetic torque will be produced. Addition electromechanical energy conversion occurs as well. The torque can be expressed as (2):

$$
\begin{aligned}
T_{e} & =\frac{3 E_{p} I_{p} \cos \varphi+3 E_{q} I_{q} \cos \varphi}{\omega_{r}} \\
& =\frac{3 \omega_{1} \lambda_{m q} I_{p} \sin \varphi+3 \omega_{2} \lambda_{m p} I_{q} \sin \varphi}{\omega_{r}}
\end{aligned}
$$

Where $E_{p}, E_{q}$ is speed induced EMF, $I_{p}, I_{q}$ is the phase current, $\varphi$ is the angle between the phase current and speed induced EMF, $\omega_{r}$ is the angular velocity of rotor, $\lambda_{m q}, \lambda_{m p}$ is mutual flux linkage when the motor excited with the phase current. And note that in the derivation, the formula $\lambda_{m p} / \lambda_{m q}=$ $I_{p} / I_{q}$ is satisfied. The will be torque can be given as follow:

$$
T_{e}=3(p+q) \lambda_{m q} I_{p} \sin \varphi
$$

From formula (3), it can be seen the electromagnetic torque production of BDFM is independent of frequency of stator winding and speed of rotor. Therefore, the torque capability of BDFM can be evaluated at a particular rotor speed. In order to achieve the higher power, the motor generally run at super-synchronous operation.

\section{Comparison of Electromagnetic Torque}

The two kinds motors' power windings are excited by three-phase AC current with the amplitude of $240 \mathrm{~A}$ and frequency of $50 \mathrm{~Hz}$, while the control windings are excited by three-phase AC current with $240 \mathrm{~A}$ and $20 \mathrm{~Hz}$, as (4)and(5). The motor operate in super-synchronous mode, and motors' speed are $840 \mathrm{r} / \mathrm{min}$.

$$
\begin{aligned}
& i_{A}=240 \cos (2 \cdot \pi \cdot 50 \cdot t) \\
& i_{B}=240 \cos \left(2 \cdot \pi \cdot 50 \cdot t-\frac{2 \pi}{3}\right) \\
& i_{C}=240 \cos \left(2 \cdot \pi \cdot 50 \cdot t+\frac{2 \pi}{3}\right) \\
& i_{a}=240 \cos (2 \cdot \pi \cdot 20 \cdot t-\theta) \\
& i_{b}=240 \cos \left(2 \cdot \pi \cdot 20 \cdot t-\frac{2 \pi}{3}-\theta\right) \\
& i_{c}=240 \cos \left(2 \cdot \pi \cdot 20 \cdot t+\frac{2 \pi}{3}-\theta\right)
\end{aligned}
$$

Changing initial phase angle $\theta$ of the excitation current in the control winding, which also means that adjusting the angle $\varphi$ between the phase current and speed induced EMF of thepower winding . The curves of electromagnetic torque versus $\theta$ are showed in Fig. 6 and the both positive and negative torque values of the motors are in Table 3 . 
Table 3. Maximum torque value

\begin{tabular}{|c|c|c|}
\hline Air-gap width $(\mathrm{mm})$ & $T_{\min }(\mathrm{N} \cdot \mathrm{m})$ & $T_{\max }(\mathrm{N} \cdot \mathrm{m})$ \\
\hline 0.8 & -1957.5 & 1969.2 \\
\hline 1.2 & -1818.8 & 1813.6 \\
\hline
\end{tabular}

The torque curves almost the same, and the angle $\theta$ between the power windings and control windings are identical when the electromagnetic torque has the maximum values for two RLR - rotor BDFMs with different air-gap width. And when the air-gap width is $0.8 \mathrm{~mm}$, both the positive and negative maximum electromagnetic torque of motor is $155.6 \mathrm{~N} . \mathrm{m}$ and $138.7 \mathrm{~N} . \mathrm{m}$ larger than $1.2 \mathrm{~mm}$ respectively. It can be seen that increasing the air-gap width, the electromagnetic torque of the motor will reduce, thereby the maximum power of the machine will also reduce.

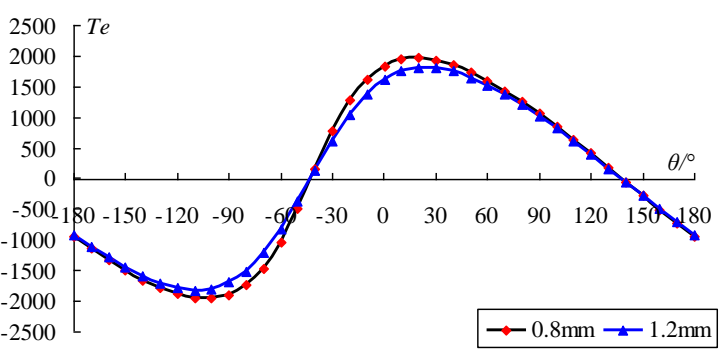

Fig 6. Curves of torque

The load voltage

The induced voltage of the power winding is an extremely important parameter while BDFMs used as generators. The voltage amplitude of fundamental harmonic and harmonic contents of the power windings are different when two motors operate in super-synchronous mode. The voltage curves of power windings from two motors are showed in Fig.7 when positive or negative peak torque is achieved.The analysis about the fundamental harmonic and harmonic contents have a certain guiding significance to the design of RLR-rotor BDFM and the filter design when connecting to the grid as generators. With the spectrum analysis of the voltage waveform in Fig.7, the DC component and the harmonic amplitude from the 1st to 15th are showed in Table 4.

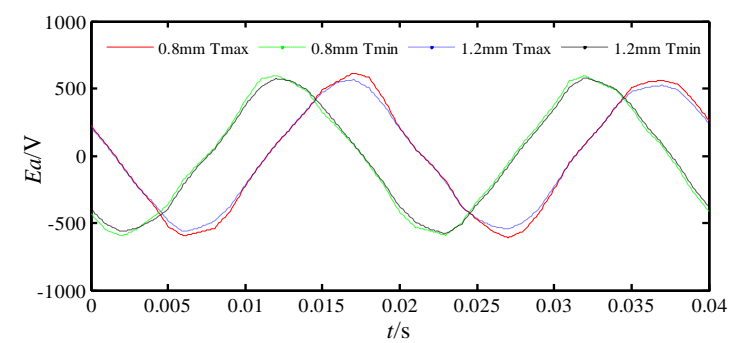

Fig 7. Load voltage of power winding 
Table 4. Harmonic contents of voltage amplitude at maximum torque

\begin{tabular}{|c|c|c|c|c|}
\hline Air-gap width $(\mathrm{mm})$ & \multicolumn{2}{|c|}{0.8} & \multicolumn{2}{c|}{1.2} \\
\hline harmonics & $V_{\operatorname{Tmax}}(\mathrm{V})$ & $V_{\operatorname{Tmin}}(\mathrm{V})$ & $V_{\operatorname{Tmax}}(\mathrm{V})$ & $V_{\mathrm{T} \min }(\mathrm{V})$ \\
\hline 0 & 1.13 & 0.9 & 0.62 & 0.48 \\
\hline 1 & 569.1 & 554.8 & 532.8 & 543.8 \\
\hline 2 & 10.78 & 1.66 & 3.6 & 2.19 \\
\hline 3 & 37.06 & 45.64 & 26.32 & 27.84 \\
\hline 4 & 11.53 & 6.57 & 5.53 & 6.27 \\
\hline 5 & 8.6 & 13.09 & 1.42 & 11.2 \\
\hline 6 & 8.21 & 5.45 & 5.77 & 3.98 \\
\hline 7 & 8.63 & 2.59 & 4.81 & 1.8 \\
\hline 8 & 1.77 & 5.05 & 1.22 & 2.74 \\
\hline 9 & 0.78 & 1.58 & 0.17 & 1.41 \\
\hline 10 & 0.87 & 1.3 & 0.39 & 0.89 \\
\hline 11 & 1.58 & 0.98 & 0.55 & 0.62 \\
\hline 12 & 1.6 & 2.29 & 1.07 & 1.2 \\
\hline 13 & 1.94 & 0.72 & 1.28 & 1.25 \\
\hline 14 & 0.86 & 1.15 & 0.69 & 0.79 \\
\hline 15 & 1.41 & 1.26 & 0.47 & 0.86 \\
\hline $\begin{array}{c}\text { The harmonic percent in } \\
\text { total harmonics }\end{array}$ & $7.57 \%$ & $8.79 \%$ & $5.31 \%$ & $5.75 \%$ \\
\hline
\end{tabular}

By comparison, it can be found that when the motor reaches the maximum positive or negative electromagnetic torque, the fundamental harmonic amplitude of power winding voltage with the $0.8 \mathrm{~mm}$ air-gap is higher than the $1.2 \mathrm{~mm}$. From the 3rd harmonic, the motor with $1.2 \mathrm{~mm}$ air-gap width is lower. From the total harmonic components, which with $1.2 \mathrm{~mm}$ air-gap is only $5.75 \%$ and $5.31 \%$, while $0.8 \mathrm{~mm}$ has reached $7.57 \%$ and $8.79 \%$. This shows that, an increase in the width of the air-gap will reduce the fundamental harmonic voltage amplitude, which also reduce its harmonic amplitude and total harmonic contents.

\section{Conclusions}

In this paper, based on the analysis of BDFM operating principle, the finite element model from two kinds of RLR-rotor BDFM with different air-gap width are built by ANSOFT, then the performance and parameters of two motors are calculated and compared. Finally, we obtain the following conclusions:

(1) Radial laminated reluctance rotor is similar to other types of rotor at magnetic field modulation.

(2) At no-load, the excitation frequency of control winding has little impact on the power winding induced EMF, and the air-gap width has a stronger impact on the induced EMF amplitude of power winding.

(3) The maximum electromagnetic torque of the motor is relevant to the phase angle difference between the two sets of winding current, therefore, maximum electromagnetic torque can be achieved by controlling the phase angle. With the increasing of air-gap width, the maximum torque of motor is reduced, but the current phase difference from two sets of winding is the same when the motor is at the maximum electromagnetic torque.

(4) The increasing of the air-gap width will reduce the fundamental harmonic voltage amplitude, but will also reduce its harmonic amplitude and total harmonic contents.

Through the analysis of the related parameters of RLR-rotor BDFM with the two kinds of air-gap width, some theory basis can be provided for optimization design and control of the motor. 


\section{References}

[1] Huijuan Liu, Longya Xu. "Performance Analysis of a Doubly Excited Brushless Machine for Variable Speed Application."International Conference on Electrical Machines and Systems, ICEMS,2011:pp.1-4

[2] Liu Huijuan, Xu Longya. "Performance analysis of doubly excited brushless machine with radially laminated magnetic barrier rotor." Transactions of China Electrotechnical Society, 2012, Vol27(7):pp.55-62

[3] Shangguan Mingzhu;Liu Huijuan,Zhang Qian."Radial laminated magnetic -barrier rotor optimization design of brushless doubly-fed machine;" Advanced Materials Research, v 383-390, 2012:pp.2195-2200

[4] Mingzhu Shangguan, Huijuan Liu. "Radial Force Analysis of Radial Laminated Magnetic-Barrier Rotor Brushless Doubly-Fed Machine;" International Conference on Engineering Materials, Energy, Management and Control, Vol.1,2011: pp.454-457.

[5] Liu C, Chau K T, Zhong J, et al. "Design and analysis of a HTS brushless doubly-fed doubly-salient machine[J]." IEEE Transactions on Applied Superconductivity, 2011, Vol21(3):pp.1119-1122

[6] Chen, X., X. Wang, and Z. Wei. "A novel structure of brushless doubly-fed machine with permanent magnets." Magnetics Conference (INTERMAG), 2015

[7] Wang, Y., Ho, S. L., Fu, W. N.,Shen, J. X. ."A Novel Brushless Doubly Fed Generator for Wind Power Generation." IEEE Transactions on Magnetics.2012,Vol48(11):pp4172-4175.

[8] Fei, Xiong, and X. Wang. "Design of a Low-Harmonic-Content Wound Rotor for the Brushless Doubly Fed Generator." IEEE Transactions on Energy Conversion .2014,29(1):pp158-168.

[9] Fei Xiong,Xuefan Wang."Development of a multi-pitch unequal-turn-coil wound rotor for the brushless doubly-fed generator;"International Conference on Electrical Machines and Systems (ICEMS),2013:pp.668 - 671

[10] S Abdi, E Abdi, A Oraee, R Mcmahon. "Optimization of Magnetic Circuit for Brushless Doubly Fed Machines." IEEE Transactions on Energy Conversion. 201530(4):pp1611-1620.

[11] Wang, Xiuping,Rui Guo,Junyou Zhao, Zhunan Jiang. "Research on design of brushless doubly fed generator." Power Engineering and Automation Conference (PEAM),IEEE,Vol(1), 2011:pp.46 - 49.

[12] Kan Chaohao, Bo Ma,Guoliang Chu,and Jiawu Zhang. "Design and electromagnetic-thermal analysis of a 64kW Doubly-sine Wound-Rotor Brushless Doubly-Fed Generator." International Conference on Electrical Machines and Systems (ICEMS), 2014:pp.1207-1212.

[13] Dorrell, D. G., A. M. Knight, and R. E. Betz. "Improvements in Brushless Doubly Fed Reluctance Generators Using High-Flux-Density Steels and Selection of the Correct Pole Numbers." Transactions on Magnetics 2011,Vol47(10):pp.4092-4095.

[14] Hashemnia, M. N., and F. Tahami. "Dynamic modeling and simulation of brushless doubly fed induction machine in consideration of core loss." IECON 2012-38th Annual Conference on IEEE Industrial Electronics Society,2012:pp.1753-1757.

[15] Zhang Fengge, Shibo Fan,Shi Jin,and Liancheng Zhu. "Modeling and SVPWM strategy of a novel dual-inverter-fed open-winding brushless doubly-fed generator for wind applications." International Conference on Electrical Machines and Systems (ICEMS), 2013:pp.422-426. 
[16] Yu, Li, et al. "Analysis of a new compound-excited doubly salient brushless DC generator with power tracking rectification." Energy Conversion Congress and Exposition (ECCE), 2015:pp. $2834-2839$

[17] Ademi, Sul, M. G. Jovanovic, and M. Hasan. "Control of Brushless Doubly-Fed Reluctance Generators for Wind Energy Conversion Systems." Transactions on Energy Conversion, 2015,Vol30(2):pp.596 - 604

[18] Zhu, Liancheng, Fengge Zhang,Shi Jin, Dairui Wang . "Research on the open winding strategy of brushless doubly-fed generator." International Transportation Electrification Conference(ITEC Asia-Pacific), 2014:pp.1-6.

[19] Logan, T., R. Mcmahon, and K. Seffen. "Noise and vibration in brushless doubly fed machine and brushless doubly fed reluctance machine."Electric Power Applications ,Iet 2014,Vol8(2):50-59. 